\title{
Endoscopic Removal of Pedunculated Leiomyoma of the Sigmoid Colon
}

\author{
Harunobu Sato ${ }^{a, b}$ Yoshihisa Mizuno $^{a}$ Tetsuya Tsukamoto $^{c}$ Tomoaki Ichikawa $^{d}$ \\ Yoshihito Kotani $^{\text {d }}$ Katsuyuki Honda ${ }^{a}$ Makoto Kuroda ${ }^{c}$ \\ a Department of Surgery, Rokuwa Hospital, Inazawa, Japan, \\ ${ }^{b}$ Department of Surgery, Fujita Health University, School of Medicine, Toyoake, Japan, \\ 'Department of Pathology, Fujita Health University, School of Medicine, Toyoake, Japan, \\ ${ }^{d}$ Department of Internal Medicine, Rokuwa Hospital, Inazawa, Japan
}

\section{Keywords}

Endoscopic therapy - Pedunculated leiomyoma .

Submucosal tumor

\section{Summary}

Background: The large bowel is a rare site for leiomyomas. Furthermore, a colonic pedunculated leiomyoma is very rare. Complete endoscopic removal of a colonic leiomyoma can be problematic because of its submucosal origin. Case Report: We report a colonic pedunculated leiomyoma that was removed by endoscopic polypectomy without complications. A 74-year-old man was referred to our hospital because of constipation. Colonoscopy demonstrated a 1-cm pedunculated polyp that was connected to a minute stalk within the sigmoid colon. It was removed by snare polypectomy. Histopathological examination demonstrated normal mucosa overlying a well-circumscribed proliferation of eosinophilic spindle cells arising in association with the muscularis mucosae. Immunohistological findings were positive for desmin and smooth muscle actin. The polyp was diagnosed as a leiomyoma. More than 9 months later, the patient remains well, with no further symptoms. Conclusion: For small, pedunculated leiomyomas, endoscopic snare polypectomy is thought to be a useful approach for both treatment and diagnosis.
Schlüsselwörter

Endoskopische Therapie - Gestieltes Leiomyom . Submukosaler Tumor

\section{Zusammenfassung}

Hintergrund: Das Kolon stellt eine seltene Lokalisation von Leiomyomen dar. Weiterhin treten gestielte Leiomyome nur sehr selten im Kolon auf. Eine vollständige endoskopische Entfernung eines Dickdarmleiomyoms kann aufgrund seines submukosalen Ursprungs problematisch sein. Fallbericht: Wir berichten von einem gestielten Dickdarmleiomyom, das mittels endoskopischer Polypektomie ohne Komplikationen entfernt wurde. Ein 74 Jahre alter Mann war aufgrund von Konstipation an unser Krankenhaus verwiesen worden. Die Kolonoskopie zeigte einen $1 \mathrm{~cm}$ großen, gestielten Polyp, der mit einem winzigen Stiel innerhalb des sigmoiden Kolons verbunden war und mittels Snare-Polypektomie entfernt wurde. Die histopathologische Untersuchung zeigte eine normale Mukosa, die eine gut abgegrenzte Proliferation von eosinophilen Spindelzellen überlagerte, welche sich gemeinsam mit der Muscularis mucosae abhoben. Der immunhistologische Befund war für Desmin und Glattmuskelaktin positiv. Der Polyp wurde als Leiomyom diagnostiziert. Mehr als 9 Monate nach dem Eingriff ist der Patient gesund und zeigte keine weiteren Symptome. Schlussfolgerung: Für kleine, gestielte Leiomyome wird die endoskopische Snare-Polypektomie als nützlicher Ansatz für sowohl die Behandlung als auch die Diagnose erachtet. 


\section{Introduction}

Smooth muscle tumors are the most common nonepithelial tumors of the gastrointestinal tract [1]. However, most gastrointestinal leiomyomas occur in the stomach and small intestine. The large bowel is a rare site for smooth muscle tumors, representing 3\% of all gastrointestinal leiomyomas [2]. Furthermore, pedunculated leiomyoma of the colon is very rare [3]. Complete endoscopic removal of this tumor can be problematic because of its submucosal origin. We herein report a pedunculated leiomyoma of the colon that was successfully removed by endoscopic snare polypectomy with no complications.

\section{Case Report}

A 74-year-old man was referred to Rokuwa Hospital, Inazawa, Japan, for investigation of constipation. He had no history of disease treatment or of smoking or drinking. His physical examination findings, including rectal examination findings, were unremarkable. All laboratory results were normal, including leukocyte, erythrocyte, and platelet counts; liver and renal function tests; C-reactive protein concentration; and urinalysis. Colonoscopy demonstrated a single, $1-\mathrm{cm}$ pedunculated polyp within the sigmoid colon (fig. 1). The polyp was smooth, round, and connected to a minute stalk. It seemed to be covered by normal mucosa. We speculated that the polyp might be a colonic mucosubmucosal elongated polyp or submucosal tumor (SMT). The polyp was removed in its entirety by snare polypectomy to clarify the diagnosis, and no complications occurred.

Histopathological examination of the tumor demonstrated normal mucosa overlying a well-circumscribed proliferation of bland, brightly eosinophilic spindle cells (fig. 2b) arising in association with the muscularis mucosa (fig. 2a). Immunohistological findings were negative for CD34, S-100 protein, vimentin, and c-Kit, but positive for desmin (fig. 2c) and smooth muscle actin. The polyp was diagnosed as a pedunculated leiomyomatous polyp.

The patient remains well more than 9 months after the procedure, with no symptoms of disease.

\section{Discussion}

Pedunculated leiomyoma of the large bowel is very rare [3]. Leiomyomas arise from the muscularis mucosa, muscularis propria, or vascular smooth muscle [1]. Leiomyomas from the muscularis propria are more likely to become symptomatic because of their size [4]. Additionally, leiomyomas from the muscularis mucosa are smaller lesions that are usually asymptomatic [4]. The propulsive forces created by peristalsis

\section{Fig. 2.}

a The lesion arose in association with the muscularis mucosa (hematoxylin and eosin staining, macroscopic view). b Histopathological examination demonstrated normal mucosa overlying a well-circumscribed proliferation of bland, brightly eosinophilic spindle cells (hematoxylin and eosin staining, 40×.

Inset: 4,200). c Immunohistochemical staining showed that the eosinophilic spindle cells were positive for desmin $(40 \times)$.
Fig. 1. Colonoscopy demonstrated a single, $1-\mathrm{cm}$ pedunculated polyp that was smooth, round, and connected to a minute stalk within the sigmoid colon. The polyp seemed to be covered by normal mucosa.
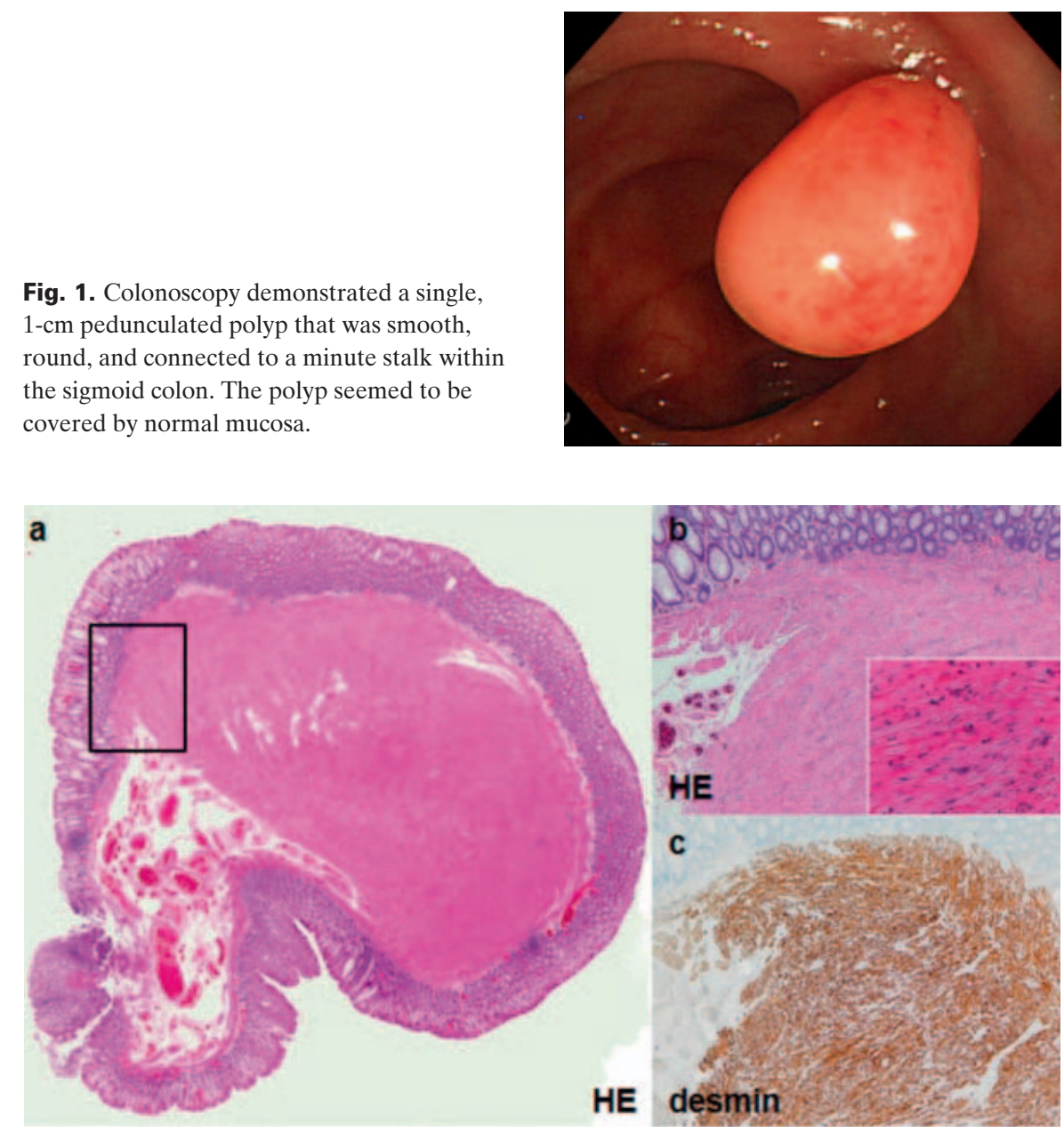
combined with the traction of the passing stool lead to the development of a pedunculated structure. However, most pedunculated SMTs of the large bowel are lipomas or lymphangiomas, and pedunculated leiomyomas of the colon are very rare [3]. The most common locations of leiomyoma in the large bowel are the sigmoid and transverse colon [5]. The gross appearance of a gastrointestinal smooth muscle tumor usually resembles an intramural or intraluminal lesion that can be similar in appearance to an adenomatous polyp [1], although a leiomyoma is basically covered by normal mucosa. In the present case, the lesion needed to be differentiated from a colonic mucosubmucosal elongated polyp or other SMT, such as a lipoma or lymphangioma. Endoscopic biopsies using large biopsy forceps or simultaneous repeated biopsies are performed for diagnosis. Radiologic imaging such as barium enemas, computed tomography with colonography, mag- netic resonance imaging, and endoscopic ultrasonography can be useful diagnostic adjuncts $[1,6]$. However, the precise diagnosis of SMT is often difficult. Complete removal is required for adequate diagnosis and treatment in most patients. In general, endoscopic removal of an SMT is often unsafe or impossible, and endoscopic removal of a colonic leiomyoma has rarely been reported. Excessive surgery must be avoided, though, because most SMTs are benign. Our experience suggests that for small, pedunculated lesions, endoscopic polypectomy is a useful approach for both treatment and diagnosis.

\section{Disclosure Statement}

The authors do not have a conflict of interest.

\section{References}

1 Chow WH, Kwan WK, Ng WF: Endoscopic removal of leiomyoma of the colon. Hong Kong Med 1997;3:325-327.

2 Lee FI: Gastric leiomyomas and leiomyosarcoma five cases. Postgrad Med J 1979;55:575-578.
3 Kawamoto K, Motooka M, Hirata N, et al: Colonic submucosal tumors: a new classification based on radiologic characteristics. Am J Roentgenol 1993; 160:315-320.

4 Björnsdóttir H, Björnsson J, Gudjónsson H: Leiomyomatous colonic polyp. Dig Dis Sci 1993;38: 1945-1947.
5 Friedman CJ, Cunningham WN, Sperling MH: Colonoscopic removal of a colonic leiomyoma. Gastrointest Endosc 1979;25:107-108.

6 Pickhardt PJ, Kim DH, Menias CO, Gopal DV, Arluk GM, Heise CP: Evaluation of submucosal lesions of the large intestine: part 1. Neoplasms. Radiographics 2007;27:1681-1692. 